BARROS, Ana Tereza Duarte Lima de; GOMES NETO, José Mario Wanderley. Liberalismo, republicanismo e democracia no marco do novo constitucionalismo latino-americano. Revista Eletrônica Direito e Política, Programa de Pós-Graduação Stricto Sensu em Ciência Jurídica da UNIVALI, Itajaí, v.10, n. 4, 30 quadrimestre de 2015. Disponível em: www.univali.br/direitoepolitica - ISSN 1980-7791.

\title{
LIBERALISMO, REPUBLICANISMO E DEMOCRACIA NO MARCO DO NOVO CONSTITUCIONALISMO LATINO-AMERICANO
}

\author{
LIBERALISM, REPUBLICANISM AND DEMOCRACY IN THE NEW LATIN \\ AMERICAN CONSTITUTIONALISM
}

\author{
Ana Tereza Duarte Lima de Barros ${ }^{1}$ \\ José Mario Wanderley Gomes Neto
}

SUMÁRIO: Introdução; 1. Contra o liberalismo, por mais direitos: uma contradição; 2. República representativa, mas nem tanto; 3. Frágeis democracias; Considerações Finais; Referências das Fontes Citadas.

\section{RESUMO}

É possível que haja democracia sem que se respeitem as garantias consagradas pela tradição liberal? Alguns países latino-americanos como a Bolívia, a Venezuela e o Equador, chegaram a criar novas constituições com o intuito de aprofundar a democracia e a cidadania. No entanto, esses países têm cada vez mais caminhado para um regime iliberal e essas constituições ajudaram a aumentar os poderes dos presidentes. O fato dessas Cartas preverem a possibilidade de o presidente convocar diretamente a cidadania tornou possível a aprovação da reeleição indefinida na Venezuela, o que desafia o próprio conceito de República. As Cartas neo-constitucionalistas aportaram grande avanço ao reconheceram os direitos dos povos indígenas, porém, os referidos países violam os direitos individuais e as eleições não se dão em condições de igualdade. Ao final, são regimes semidemocráticos, sendo a Venezuela, mais especificamente, uma forma de autoritarismo competitivo.

PALAVRAS-CHAVE: Liberalismo; Republicanismo; Democracia; Novo Constitucionalismo.

\footnotetext{
${ }^{1}$ Mestranda em Ciência Política pela Universidade Federal de Pernambuco. Bolsista de mestrado do CNPq. Bacharela em Direito pela Universidade Católica de Pernambuco. Recife-PE-Brasil. E-mail: anaterezadlb@gmail.com.

2 Doutor em Ciência Política e Mestre em Direito pela Universidade Federal de Pernambuco. Professor de Direito da Universidade Católica de Pernambuco. Recife-PE-Brasil. E-mail: josemwgomes@gmail.com.
} 
BARROS, Ana Tereza Duarte Lima de; GOMES NETO, José Mario Wanderley. Liberalismo, republicanismo e democracia no marco do novo constitucionalismo latino-americano. Revista Eletrônica Direito e Política, Programa de Pós-Graduação Stricto Sensu em Ciência Jurídica da UNIVALI, Itajaí, v.10, n. 4, 30 quadrimestre de 2015. Disponível em: www.univali.br/direitoepolitica - ISSN 1980-7791.

\section{ABSTRACT}

Is it possible for a democracy to survive without respecting the guarantees enshrined by the liberal tradition? Some Latin American countries like Bolivia, Venezuela and Ecuador created new constitutions in order to deepen democracy and citizenship. However, these countries have been walking towards an illiberal regime and these constitutions have helped to increase the powers of presidents. The fact that these letters provide the possibility for the President to convoke citizens directly made possible the approval of indefinite re-election in Venezuela, which challenges the very concept of Republic. The neo-constitutionalist Letters breakthrough is the recognition of the rights of indigenous peoples. However, these countries violate individual rights and elections do not take place on equal terms. Lastly, they are semi-democratic regimes, and Venezuela, more specifically, a form of competitive authoritarianism (Levitsky, WAY, 2010).

KEYWORDS: Liberalism; Republicanism; Democracy; New Constitutionalism.

\section{INTRODUÇÃO}

A visão predominante entre os constitucionalistas é a de que a cultura jurídica latino-americana é eurocêntrica, tendo incorporado a doutrina liberal-individualista e a filosofia positivista ao seu ordenamento ${ }^{3}$, notadamente influenciada pelas constituições liberais burguesas dos Estados Unidos (1787) e da França (1791 e 1793), e pelo ideário individualista e patrimonial da legislação napoleônica (1804) e do estatuto privado germânico $(1900)^{4}$.

Foi notável a influência do individualismo liberal e do ideário iluminista dos Direitos do Homem, tendo as constituições abarcado abstratamente vários direitos consagrados pela tradição liberal, tratando a cidadania como sendo culturalmente homogênea e idealizando um Estado de Direito universal ${ }^{5}$.

\footnotetext{
${ }^{3}$ WOLKMER, Antônio Carlos. Pluralismo e crítica do constitucionalismo na América Latina. In: Anais do IX Simpósio Nacional de Direito Constitucional. 2010, Curitiba. Anais. Curitiba: ABDConst., 2010. p. 145.

${ }^{4}$ ANDRADE Apud WOLKMER, Antônio Carlos. Pluralismo e crítica do constitucionalismo na América Latina. In: Anais do IX Simpósio Nacional de Direito Constitucional. 2010, Curitiba. Anais. Curitiba: ABDConst., 2010. p. 146.

${ }^{5}$ WOLKMER, Antônio Carlos. Pluralismo e crítica do constitucionalismo na América Latina. In: Anais do IX Simpósio Nacional de Direito Constitucional. 2010, Curitiba. Anais. Curitiba: ABDConst., 2010. p. 147.
} 
BARROS, Ana Tereza Duarte Lima de; GOMES NETO, José Mario Wanderley. Liberalismo, republicanismo e democracia no marco do novo constitucionalismo latino-americano. Revista Eletrônica Direito e Política, Programa de Pós-Graduação Stricto Sensu em Ciência Jurídica da UNIVALI, Itajaí, v.10, n. 4, $3^{\circ}$ quadrimestre de 2015. Disponível em: www.univali.br/direitoepolitica - ISSN 1980-7791.

A proposta das constituições, fruto da doutrina constitucional "novo constitucionalismo latino-americano", é romper com esse constitucionalismo liberal importado e construir um Estado que reconheça que a sociedade latinoamericana não é homogênea, mas plural, dando voz a grupos antes excluídos do processo político, como os povos indígenas.

Na primeira parte do artigo é explorado como o novo constitucionalismo lida com o liberalismo, expondo a contradição existente entre incorporar mais direitos e colocar os direitos individuais em segundo plano.

Na segunda parte é analisada a forma de republicanismo adotada por essas constituições, que desafia a clássica tripartição de poderes e mistura e representação tradicional com instrumentos da democracia direta. Questiona-se se a democracia direta serviu para dar maiores poderes ao presidente e se é possível que, em uma república, o chefe do Executivo possa se reeleger indefinidamente, como ocorre na Venezuela.

Por fim, questiona-se se, de fato, os regimes existentes na Venezuela, Bolívia e Equador podem ser considerados democracias participativas, uma vez que, para ser uma democracia participativa é necessário, primeiramente, ser uma democracia. Conclui-se que os regimes existentes nesses países são híbridos, sendo a Venezuela, mais especificamente, um caso de autoritarismo competitivo.

\section{CONTRA O LIBERALISMO, POR MAIS DIREITOS: UMA CONTRADIÇÃO}

O novo constitucionalismo latino-americano rechaça a visão clássica liberal, como a defendida por Marshall, de que a função da cidadania seria assegurar que todos os membros da sociedade sejam tratados como iguais e, através da garantia de direitos civis, políticos e sociais, sintam-se membros completos da sociedade ${ }^{6}$.

A principal diferença entre o constitucionalismo liberal e o novo constitucionalismo latino-americano está na diferença de conteúdo que dão "às construções de

\footnotetext{
${ }^{6}$ MARSHALL, Tomas. Ciudadania y clase social. Madrid: Alianza Editorial, 1998. p. 22-36.
} 
BARROS, Ana Tereza Duarte Lima de; GOMES NETO, José Mario Wanderley. Liberalismo, republicanismo e democracia no marco do novo constitucionalismo latino-americano. Revista Eletrônica Direito e Política, Programa de Pós-Graduação Stricto Sensu em Ciência Jurídica da UNIVALI, Itajaí, v.10, n. 4, 30 quadrimestre de 2015. Disponível em: www.univali.br/direitoepolitica - ISSN 1980-7791.

nação, direitos (individuais, sociais e políticos), cidadania e nas diferentes formas de conceber e desenhar o governo democrático"7 ${ }^{7}$. Assim, diferentemente do constitucionalismo liberal, não coloca no centro o indivíduo, mas a sociedade, que é anterior a este ${ }^{8}$. Dessa forma, reconhece a titularidade de direitos a pessoas coletivas, como comunidades e nacionalidades ${ }^{9}$.

Qualificado como constitucionalismo $\sin$ padres $^{10}$, caracterizou-se pela sua "legitimidade", advinda das Assembleias constituintes convocados com a finalidade específica de redigir essas novas constituições, tendo seu processo contado com a participação ativa de diferentes setores sociais. Ademais, após findo o processo legislativo, foi submetida a referendo popular.

É enorme a gama de novos direitos incorporados por ditas constituições. Dentre eles, destaco a ampla proteção das minorias étnicas e grupos originários, que inclui a admissão de uma justiça própria que leva em consideração seus princípios, sua cultura, e a legitimação de uma ampla quantidade de direitos. Além do mais, terão esses grupos direito a serem consultados antes de que se adote qualquer medida legislativa que afete seus direitos coletivos ${ }^{11}$.

No âmbito judicial, foram vários os dispositivos incorporados, como a ação de defesa, a ação de amparo constitucional, a ação de proteção da privacidade, a ação de inconstitucionalidade, a ação de cumprimento, a ação popular, a ação de amparo à liberdade e à segurança, a ação de proteção, o habeas corpus, a ação de habeas data, a ação por cumprimento, a ação extraordinária de proteção, a

\footnotetext{
7 Tradução própria.

8 JARAMILLO, Svetlana. El nuevo constitucionalismo y los rezagos de la ciencia del Derecho Constitucional latinoamericano. Buenos Aires: CLACSO, 2013. p. 23-24.

${ }^{9}$ ARMENGOL, Carlos Manuel Villabella. Constitución y democracia en el nuevo constitucionalismo latinoamericano. IUS. Revista del Instituto de Ciencias Jurídicas de Puebla A.C. n. 25, 2010. p. 61.

10 VICIANO PASTOR, Roberto; MARTÍNEZ DALMAU, Ruben ¿Se puede hablar de un nuevo Constitucionalismo Latinoamericano como corriente doctrinal sistematizada? Universidad de Valencia, 2010. p. 8.

11 ARMENGOL, Carlos Manuel. Constitución y democracia en el nuevo constitucionalismo latinoamericano. IUS. Revista del Instituto de Ciencias Jurídicas de Puebla A.C. n. 25, 2010. p. $59 / 61$.
} 
BARROS, Ana Tereza Duarte Lima de; GOMES NETO, José Mario Wanderley. Liberalismo, republicanismo e democracia no marco do novo constitucionalismo latino-americano. Revista Eletrônica Direito e Política, Programa de Pós-Graduação Stricto Sensu em Ciência Jurídica da UNIVALI, Itajaí, v.10, n. 4, 30 quadrimestre de 2015. Disponível em: www.univali.br/direitoepolitica - ISSN 1980-7791.

defensoria do povo. Além do mais, criou-se a reclamação por omissão caso a autoridade competente não cumpra a norma ${ }^{12}$.

A incorporação de tantos direitos ao texto constitucional aparenta aprofundar a democracia, contudo, será que ditos países respeitam, de fatos, todos esses direitos?

É de se aplaudir o reconhecimento de direitos a grupos antes excluídos do processo político, no entanto, Venezuela, Bolívia e Equador, especialmente a Venezuela, violam substancialmente os direitos individuais. Daí surge a pergunta: é possível que haja democracia sem que se respeitem os direitos promovidos pela tradição liberal?

Segundo O'Donnell e Schmitter, liberalização é o processo que amplia e redefine os direitos. Estas garantias clássicas da tradição liberal "protegem indivíduos e grupos sociais ante os atos arbitrários ou ilegais cometidos pelo Estado ou por terceiros". Se não se garantem estes direitos, a democracia se transforma em um mero formalismo ${ }^{13}$. É o que ocorre, por exemplo, na Venezuela, onde se garantem as eleições livres, mas existem pressões, há impedimentos à livre concorrência, os juízes são parciais e não se garante o devido processo legal (o heabeas corpus, por exemplo, é concedido de modo arbitrário).

Outro traço característico de ditos países, especialmente da Venezuela e do Equador, é o desrespeito às liberdades de expressão e comunicação, traduzidos na constante perseguição aos meios de comunicação contrários ao regime, em que um dos casos mais emblemáticos foi a não renovação, pelo Estado venezuelano, da concessão que a emissora de televisão Radio Caracas de Televisión (RCTV) tinha para operar utilizando um dos espectros radioelétricos disponíveis.

Dia 27 de março de 2007 o canal de TV aberto, intitulado Radio Caracas de Televisión (RCTV), foi notificado de que não teria a sua concessão renovada, após um trâmite processual marcado pela falta de imparcialidade e transparência, em

\footnotetext{
12 ARMENGOL, Carlos Manuel. Constitución y democracia en el nuevo constitucionalismo latinoamericano. IUS. Revista del Instituto de Ciencias Jurídicas de Puebla A.C. n. 25, 2010. p. 62.

13 O'DONNELL, Guillermo; SCHMITTER, Philippe. Transiciones desde un gobierno autoritario. Conclusiones tentativas sobre las democracias inciertas. Buenos Aires: Paidós, 1988. v. 4. p. 21.
} 
BARROS, Ana Tereza Duarte Lima de; GOMES NETO, José Mario Wanderley. Liberalismo, republicanismo e democracia no marco do novo constitucionalismo latino-americano. Revista Eletrônica Direito e Política, Programa de Pós-Graduação Stricto Sensu em Ciência Jurídica da UNIVALI, Itajaí, v.10, n. 4, 30 quadrimestre de 2015. Disponível em: www.univali.br/direitoepolitica - ISSN 1980-7791.

que até o próprio canal de TV, que era parte, teve o seu direito de intervir para ser ouvido e oferecer provas negado, violando as regras processuais em vigência na Venezuela ${ }^{14}$. Em decorrência das violações ao direito de defesa, ao devido processo legal, à liberdade de expressão, à igualdade perante a lei, dentre outros direitos alegados pela emissora postulante, foi o caso levado à Comissão Interamericana de Direitos Humanos, que concluiu pelo caráter político da decisão que não renovou a concessão do canal, vez que este tinha posicionamento contrário ao oficialismo, tendo sido a emissora acusada de golpista pelo então presidente Hugo Chávez e pelo seu ministro das telecomunicações.

Ou seja, embora a constituição venezuelana proteja o direto ao devido processo legal, a igualdade perante a lei e os direitos à liberdade de expressão e comunicação, os referidos direitos não são respeitados.

A Venezuela, recentemente, também encarcerou líderes da oposição, colocando seu status de democracia, que já a algum tempo anda sendo questionado, definitivamente em cheque.

Interessante que Simón Bolívar é considerado o "pai libertador" de Venezuela, Bolívia e Equador, sendo por sua causa que ditos países são denominados "bolivarianos". Era Bolívar contrário aos direitos consagrados na Declaração dos Direitos do Homem e do Cidadão. Nas palavras de Gargarella e Courtis:

Para tomar um caso como relevante, poderíamos dizer que Bolívar repudiava, como tantos, a fascinação de seus opositores com as "máximas exageradas dos direitos do homem" - máximas as quais ele desqualificava por serem importadas da França. Contudo, sua reivindicação pelo local não chegava muito longe: todos os projetos constitucionais bolivarianos se baseavam seja no constitucionalismo conservador inglês, seja no constitucionalismo autoritário napoleônico ${ }^{15}$.

\footnotetext{
${ }^{14} \mathrm{CIDH}$. Informe No. 112/12. Caso 12.828. Fondo Marcel Granier y otros Venezuela. 2012. p. 46. Disponível em: http://search.oas.org/en/default.aspx?k=Informe+No.+112\%2f12.+Caso+12.828\&s=All+Sites. Acesso em: 02 de dezembro de 2013.
}

15 Tradução própria. GARGARELLA, Roberto; COURTIS, Christian. El nuevo consititucionalismo latino-americano: promesas e interrogantes. Santiago: Naciones Unidas, 2009. p. 24. 
BARROS, Ana Tereza Duarte Lima de; GOMES NETO, José Mario Wanderley. Liberalismo, republicanismo e democracia no marco do novo constitucionalismo latino-americano. Revista Eletrônica Direito e Política, Programa de Pós-Graduação Stricto Sensu em Ciência Jurídica da UNIVALI, Itajaí, v.10, n. 4, $3^{\circ}$ quadrimestre de 2015. Disponível em: www.univali.br/direitoepolitica - ISSN 1980-7791.

Guillermo O'Donnell chama atenção para o fato de que a América Latina necessita

Empreender lutas liberais pela efetividade de direitos civis formais e universalistas para todos, ainda se nas origens da poliarquia, o liberalismo as vezes (e com frequência na história da América Latina) atuou como freio aos impulsos democráticos ${ }^{16}$.

O reconhecimento do pluralismo existente na sociedade latino-americana, dotando as minorias étnicas e os povos originários de direitos não antes reconhecidos, foi o carro chefe e o grande triunfo dessas novas constituições latino-americanas. Contudo, sem um Estado que proteja os direitos tradicionalmente promovidos pelo liberalismo (e que chegam a ser, formalmente, assegurados pelas referidas constituições), especialmente os direitos individuais, não há democracia.

\section{REPÚBLICA REPRESENTATIVA, MAS NEM TANTO}

Montesquieu cria uma tipologia na qual existem três regimes políticos: a república, a monarquia e o despotismo. A república estaria dividida em dois tipos: a república democrática e a república aristocrática. Na república democrática, "o povo inteiro" é dono do poder soberano, e não apenas uma minoria pertencente à aristocracia $^{17}$.

O autor, ao fazer uma análise das leis eleitorais, observa que o povo não é apto para governar, devendo apenas indicar quem deve exercer essa função. A partir dessa premissa, Montesquieu cria a ideia de governo representativo, que é adotada até os dias atuais. Ademais, Montesquieu, salienta a importância de se ter uma divisão de poderes, uma vez que só se houver equilíbrio entre eles haverá liberdade ${ }^{18}$.

\footnotetext{
16 O’DONNELL, Guillermo. Disonancias. Críticas democráticas a la democracia. Buenos Aires: Prometeo Libros, 2007. p. 177.

17 ARCAYA, Óscar Godoy. Republicanismo, liberalismo y democracia. Estudios Públicos. n. 99, 2005. p. 250.

18 ARCAYA, Óscar Godoy. Republicanismo, liberalismo y democracia. Estudios Públicos. n. 99, 2005. p. 251.
} 
BARROS, Ana Tereza Duarte Lima de; GOMES NETO, José Mario Wanderley. Liberalismo, republicanismo e democracia no marco do novo constitucionalismo latino-americano. Revista Eletrônica Direito e Política, Programa de Pós-Graduação Stricto Sensu em Ciência Jurídica da UNIVALI, Itajaí, v.10, n. 4, 30 quadrimestre de 2015. Disponível em: www.univali.br/direitoepolitica - ISSN 1980-7791.

Concordam com Montesquieu diversos outros teóricos, como J.S. Mills ${ }^{19}$ e Hans Kelsen. Nas palavras de Kelsen: "Não é possível que todos os indivíduos submetidos às normas do Estado participem na sua criação, que é a forma necessária de exercício do poder $(\ldots)^{\prime 20}$. Assim, os partidos "agrupam homens de mesma opinião para Ihes assegurar uma influência real no manejo dos assuntos públicos ${ }^{21}$.

Tanto a Venezuela, quanto a Bolívia, como o Equador adotaram a forma republicana. No entanto, não nos moldes formais. Adotaram uma forma de república comunitária, que reconhece que a tomada de decisões futuras se encontra no passado, assentadas nas tradições da comunidade ${ }^{22}$. Um modelo que mistura a clássica representação com mecanismos da democracia direta e participativa. Assim, a democracia representativa restou parcialmente anulada ${ }^{23}$. Instrumentalizaram uma democracia inclusiva, menos formal, mais substantiva, sem, contudo, descartar a democracia representativa ${ }^{24}$.

As lideranças existentes na Venezuela, Bolívia e Equador a finais do século XX surgiram em momentos de profunda crise institucional. Os cidadãos não se sentiam representados pelos partidos políticos, que não conseguiam absorver as demandas sociais, assim que resolveram eleger políticos que não pertenciam a nenhum dos partidos tradicionais. Estes líderes, uma vez eleitos, passaram a incluir pessoas e grupos sociais que antes estavam excluídos do sistema ${ }^{25}$.

${ }^{19}$ MILLS, J.S. (1859). On Liberty and Other Writings. Cambridge: Cambridge University Press, 1989.

20 Tradução própria.

${ }^{21}$ Tradução própria. KELSEN, Hans. (1929). La Démocratie. Paris: Sa Nature - Sa Valeur, 1988. p. 27-28.

${ }^{22}$ GARGARELLA, Roberto. El republicanismo y la filosofia política contemporânea. Teoría y filosofía política. La recuperación de los clásicos en el debate latinoamericano. Buenos Aires: CLACSO, 2001. p. 31.

${ }^{23}$ JARAMILLO, Svetlana. El nuevo constitucionalismo y los rezagos de la ciencia del Derecho Constitucional latinoamericano. Buenos Aires: CLACSO, 2013. p. 31.

24 ORIO, Luís Henrique. Um novo cenário para novos protagonistas: as ordens políticas do novo constitucionalismo latinoamericano. In: Anais XXII Encontro Nacional do CONPEDI. 2013, Curitiba. Anais. Florianópolis: FUNJAB, 2013. p. 37.

${ }^{25}$ FREIDENBERG, Flavia. Los nuevos liderazgos populistas y la democracia en América Latina. Lasa Forum, v. 42, n. 03, 2011. p. 9. 
BARROS, Ana Tereza Duarte Lima de; GOMES NETO, José Mario Wanderley. Liberalismo, republicanismo e democracia no marco do novo constitucionalismo latino-americano. Revista Eletrônica Direito e Política, Programa de Pós-Graduação Stricto Sensu em Ciência Jurídica da UNIVALI, Itajaí, v.10, n. 4, 30 quadrimestre de 2015. Disponível em: www.univali.br/direitoepolitica - ISSN 1980-7791.

Assim, o sistema republicano representativo encontrava-se claramente em crise, o que impulsionou o surgimento de novas lideranças, que logo reivindicaram uma nova forma de democracia constitucional.

Essas constituições começam por desafiar a tripartição de poderes clássica descrita por Montesquieu. Na Venezuela, o poder público foi dividido nos Poderes Legislativo, Executivo, Judiciário, Cidadão e Eleitoral. No Equador, a divisão de poderes compreende o Legislativo, o Judiciário, o Executivo, o Eleitoral e o poder de transparência e controle social ${ }^{26}$.

Defende uma república que inclui formas democráticas direta e participativa, dada a falência do sistema representativo. Essa democracia participativa encontra fundamento em Rousseau, quem encontrava ser inconcebível a representação ${ }^{27}$. É - que Boa Ventura de Sousa Santos chamou de "democracia de alta intensidade"28. Dentre os principais instrumentos da democracia direta encontrados nessas constituições podemos citar "a eleição para cargos públicos, o referendo, a consulta popular, a revocatória de mandato, a iniciativa legislativa, constitucional e constituinte, o cabildo e a assembleia de cidadãos e cidadãs, entre outros" 29 .

A partir de todo o exposto até o momento, acerca da inclusão de mecanismos da democracia direta nos novos textos, cabe fazermos uma indagação: essa participação política ativa é compatível com o hiperpresidencialismo que as novas constituições, além de manter, reforçaram? É verdade que ditas constituições buscaram criar mecanismos para avançar na proteção de direitos individuais e de

${ }^{26}$ ORIO, Luís Henrique. Um novo cenário para novos protagonistas: as ordens políticas do novo constitucionalismo latinoamericano. In: Anais XXII Encontro Nacional do CONPEDI. 2013, Curitiba. Anais. Florianópolis: FUNJAB, 2013. p. 41/43.

27 ORIO, Luís Henrique. Um novo cenário para novos protagonistas: as ordens políticas do novo constitucionalismo latinoamericano. In: Anais XXII Encontro Nacional do CONPEDI. 2013, Curitiba. Anais. Florianópolis: FUNJAB, 2013. p. 42/44-45.

${ }^{28}$ SANTOS, Boa Ventura de Sousa. Renovar a Teoria Crítica e reiventar a emancipação social. São Paulo: Boitempo, 2007.

29 ORIO, Luís Henrique. Um novo cenário para novos protagonistas: as ordens políticas do novo constitucionalismo latinoamericano. In: Anais XXII Encontro Nacional do CONPEDI. 2013, Curitiba. Anais. Florianópolis: FUNJAB, 2013. p. 48. 
BARROS, Ana Tereza Duarte Lima de; GOMES NETO, José Mario Wanderley. Liberalismo, republicanismo e democracia no marco do novo constitucionalismo latino-americano. Revista Eletrônica Direito e Política, Programa de Pós-Graduação Stricto Sensu em Ciência Jurídica da UNIVALI, Itajaí, v.10, n. 4, 30 quadrimestre de 2015. Disponível em: www.univali.br/direitoepolitica - ISSN 1980-7791.

coletividades, porém, não há como negar que o "motor" de ditas reformas constitucionais foi a reeleição presidencial ${ }^{30}$.

Esse sistema hiperpresidencialista foi considerado por muitos a causa principal do porquê as democracias da região não conseguiam se manter no tempo, mas é claro que os presidentes não iriam impulsionar reformas que iriam de encontro a seus próprios interesses ${ }^{31}$.

Como bem explicam Roberto Gargarella e Christian Courtis, a relação entre o fortalecimento do poder presidencial e a promoção da participação popular é contraditória, uma vez que,

O ideal da democracia participativa requer descentralizar e desconcentrar o poder, e não o contrário. Fazer ambas coisas ao mesmo tempo (fortalecer o presidente-abrir espaços para mais participação) costuma resultar numa operação contraditória, que acarreta o grave risco de que um dos lados ideais ou objetivos termine resultando opaco ou diretamente apagado $^{32}$.

O que ocorre é que, mesmo que essas novas constituições tenham introduzido novos mecanismos de controle popular frente ao poder, a relação entre essas seções da constituição não é igualitária. O Poder Executivo se encontra em situação de privilégio para impor sua vontade aos que buscarem obstaculizá-la ${ }^{33}$.

Um dos principais mecanismos desenvolvidos pelo liberalismo foi justamente o sistema de freios e contrapesos, para que os poderes pudessem controlar-se mutuamente. Dessa forma, o liberalismo tomou algumas medidas como "a proibição da delegação de faculdades extraordinárias para os governantes" e, a

\footnotetext{
${ }^{30}$ GARGARELLA, Roberto. Cambiar la letra, cambiar el mundo. Revista Ecuador Debate, n. 75, 2008. p. 94-95.

31 GARGARELLA, Roberto. El constitucionalismo latinoamericano y la "sala de máquinas" de la Constitución (1980-2010). Gaceta Constitucional, n. 48, 2011. p. 291-292.

32 Tradução própria. GARGARELLA, Roberto; COURTIS, Christian. El nuevo consititucionalismo latino-americano: promesas e interrogantes. Santiago: Naciones Unidas, 2009. p. 29.

33 GARGARELLA, Roberto. El constitucionalismo latinoamericano y la "sala de máquinas" de la Constitución (1980-2010). Gaceta Constitucional, n. 48, 2011. p. 294.
} 
BARROS, Ana Tereza Duarte Lima de; GOMES NETO, José Mario Wanderley. Liberalismo, republicanismo e democracia no marco do novo constitucionalismo latino-americano. Revista Eletrônica Direito e Política, Programa de Pós-Graduação Stricto Sensu em Ciência Jurídica da UNIVALI, Itajaí, v.10, n. 4, 30 quadrimestre de 2015. Disponível em: www.univali.br/direitoepolitica - ISSN 1980-7791.

"limitação dos poderes normativos do presidente" 34 . O que acontece é que essas novas constituições dotaram os presidentes de amplas faculdades legislativas, dentre as quais destaco a possibilidade de ser ele quem convoca a cidadania para referendos, o que mitiga, em parte, a capacidade do Legislativo de fazer contrapeso ao Executivo. Dessa forma, podem os presidentes terem a sua vontade satisfeita sem passar pelo crivo do Legislativo.

Em trabalho anterior destacamos que

O princípio da separação de poderes é o fundamento da democracia presidencialista. O novo constitucionalismo latinoamericano aceita e promove a mitigação desse princípio sob a falsa justificativa de que através desses referendos promovidos pelo Executivo se escutaria a vontade do poder constituinte. Contudo, é evidente que o poder constituinte, ao eleger seus legisladores, já está demonstrando sua vontade, uma vez que o parlamento é representante direto dos cidadãos e, portanto, é quem deve convocar a cidadania para decidir a respeito de mudanças constitucionais, não 0 presidente ${ }^{35}$.

Aqui, mais uma vez, cabe relembrar que Simón Bolívar, o "pai libertador" e herói maior dessas três nações, defendia a visão conservadora hiperpresidencialista

Abandonemos as formas federais que nãos nos convém,
abandonemos o triunvirato do poder executivo e,
concentrando-o em um presidente, confiemos-lhe a
autoridade suficiente para que consiga se manter lutando
contra os inconvenientes anexos a nossa recente situação, ao
estado de guerra que sofremos, e à espécie dos inimigos
externos e domésticos, contra quem teremos longo tempo
para combater $(\ldots)^{36}$.

34 OLIVEIRA, Daltro Alberto Jaña Marques; MAGRANI, Eduardo José Guedes; VIEIRA, José Ribas; GUIMARÃES, José Miguel Gomes de Faria Guimarães. Revista Quaestio Iuris, v. 6, n. 2, 2013. p. 201.

35 BARROS, Ana Tereza Duarte Lima de; GOMES NETO, José Mario Wanderley. Nuevo constitucionalismo latinoamericano: una vía para la legitimación del hiperpresidencialismo en las democracias populistas. In: XI Congreso Nacional y IV Congreso Internacional sobre Democracia, 2014, Rosario. Congreso sobre democracia, entre el malestar y la innovación: los nuevos retos para la democracia en América Latina. Rosario: UNR Editora, 2014.

36 BOLÍVAR, Simón. Escritos Políticos. México: Porrúa, 1986. p. 110. 
BARROS, Ana Tereza Duarte Lima de; GOMES NETO, José Mario Wanderley. Liberalismo, republicanismo e democracia no marco do novo constitucionalismo latino-americano. Revista Eletrônica Direito e Política, Programa de Pós-Graduação Stricto Sensu em Ciência Jurídica da UNIVALI, Itajaí, v.10, n. 4, 30 quadrimestre de 2015. Disponível em: www.univali.br/direitoepolitica - ISSN 1980-7791.

Assim, os conservadores do século XIX, como era Bolívar, redigiram constituições que outorgavam ao Executivo mandatos de longa duração, com possibilidade de reeleição, ou inclusive, com mandatos vitalícios ${ }^{37}$.

Resta aparente que os presidentes desses três países compartilhavam da mesma opinião de seu líder. Na Venezuela, por exemplo, "encontramos um texto amplo em termos de participação popular, mas que preserva amplíssimos poderes e margens de ação ao órgão executivo" ${ }^{38}$.

No Equador, o Presidente da República pôs logo limites à participação popular, vetando seis artigos da lei de participação cidadã, além da disposição transitória e, assim, desencorajando a participação cívica prevista na Constituição. Ou seja, o presidente vetou uma iniciativa legislativa que estava destinada a colocar em funcionamento os dispositivos criados na nova Constituição ${ }^{39}$. Dentre os artigos vetados, encontra-se dispositivos que rezavam que as distintas funções do Estado deveriam estabelecer mecanismos para garantir a transparência de suas ações, assim como planos e programas que facilitassem a participação ativa da cidadania $(\text { art. } 45)^{40}$.

Na Venezuela, foi feita uma lista, a chamada Lista Tascón, com o nome de todos os que convocaram campanha, em 2004, para revocar o mandado do então presidente Hugo Chávez. Dita lista foi considerada uma ameaça àqueles que haviam decidido aceitar participar politicamente de tal campanha de recall ${ }^{41}$.

Ainda na Venezuela, foram várias as consultas populares convocadas com a intenção de ser "um plebiscito sobre Chávez e seu projeto político"42, a exemplo

\footnotetext{
37 NEGRETTO, Gabriel. La Genealogia del Republicanismo Liberal en América Latina. Alberdí y la Constitución Argentina de 1853. In: Latin American Studies Association. 2001, Washington DC. Anais. p. 10-11.

38 GARGARELLA, Roberto. El constitucionalismo latinoamericano y la "sala de máquinas" de la Constitución (1980-2010). Gaceta Constitucional, n. 48, 2011. p. 298.

39 GARGARELLA, Roberto. El constitucionalismo latinoamericano y la "sala de máquinas" de la Constitución (1980-2010). Gaceta Constitucional, n. 48, 2011. p. 297.

40 OAS. Ley Orgánica de Participación Ciudadana. 2010. p. 14. Disponível em: http://www.oas.org/juridico/PDFs/mesicic4_ecu_org6.pdf. Acesso em: 10 de jul. 205.

41 GARGARELLA, Roberto. El constitucionalismo latinoamericano y la "sala de máquinas" de la Constitución (1980-2010). Gaceta Constitucional, n. 48, 2011. p. 298-299.

42 Tradução própria.
} 
BARROS, Ana Tereza Duarte Lima de; GOMES NETO, José Mario Wanderley. Liberalismo, republicanismo e democracia no marco do novo constitucionalismo latino-americano. Revista Eletrônica Direito e Política, Programa de Pós-Graduação Stricto Sensu em Ciência Jurídica da UNIVALI, Itajaí, v.10, n. 4, 30 quadrimestre de 2015. Disponível em: www.univali.br/direitoepolitica - ISSN 1980-7791.

do referendo de 2004, quando se colocou em questão a continuidade do presidente (60\% votou pelo "sim"). No dia 15 de agosto de 2007, o então presidente da Venezuela, Hugo Chávez, apresentou uma proposta de reforma que modificava 33 artigos da Constituição (este número passou para 69 depois que a Assembleia Nacional agregou outras modificações), dentre elas, a que limitava o mandato presidencial. No dia 2 de dezembro de 2007, dia do referendo, o presidente Chávez recebeu o seu primeiro rechaço cidadão (49.36\% de votos favoráveis contra 50.7\%). Essa proposta de reforma se deu sem a participação de outros atores políticos e sociais. Ademais, o debate público foi limitado, daí os chavistas que antes o apoiavam questionaram uma proposta de referendo que se deu sem prévia consulta. Apesar de que esses chavistas defendiam o socialismo, rechaçavam o modelo cubano, a inspiração de Chávez ${ }^{43}$.

Contudo, um rechaço cidadão não é problema para um bom líder populista. Assim, o que passou foi que,

Dia 30 de novembro de 2008, Chávez ordenou a seus seguidores ativar um processo de emenda que lhe permitisse postular como candidato a um terceiro mandato de seis anos nas eleições presidenciais de 2012, e assim sucessivamente (...) Dia 15 de fevereiro de 2009, com uma votação de $54.86 \%$ frente a $45.1 \%$, aprovou-se em um referendo a reforma que habilita a reeleição de maneira indefinida para qualquer cargo de eleição popular (incluída a presidência) ${ }^{44}$.

Dessa maneira, é notável que "a democracia direta na Venezuela tendeu a reforçar o poder do presidente as custas de outros mecanismos de representação, como os partidos políticos e as organizações sociais autônomas" ${ }^{45}$.

\footnotetext{
43 LISSIDINI, A. Democracia directa en Uruguay y en Venezuela: nuevas voces, antiguos procesos. In: Cameron, Hershberg y Sharpe, Nuevas instituciones de democracia participativa en América Latina. México: Flacso, 2012. p. 487/490-4931

${ }^{44}$ Tradução própria. LISSIDINI, A. Democracia directa en Uruguay y en Venezuela: nuevas voces, antiguos procesos. In: Cameron, Hershberg y Sharpe, Nuevas instituciones de democracia participativa en América Latina. México: Flacso, 2012. p. 493.

45 Tradução própria. LISSIDINI, A. Democracia directa en Uruguay y en Venezuela: nuevas voces, antiguos procesos. In: Cameron, Hershberg y Sharpe, Nuevas instituciones de democracia participativa en América Latina. México: Flacso, 2012. p. 499.
} 
BARROS, Ana Tereza Duarte Lima de; GOMES NETO, José Mario Wanderley. Liberalismo, republicanismo e democracia no marco do novo constitucionalismo latino-americano. Revista Eletrônica Direito e Política, Programa de Pós-Graduação Stricto Sensu em Ciência Jurídica da UNIVALI, Itajaí, v.10, n. 4, 30 quadrimestre de 2015. Disponível em: www.univali.br/direitoepolitica - ISSN 1980-7791.

Se um país que adota a forma de governo republicana aprovou a reeleição por tempo indefinido, resta-me perguntar: o que é uma República? Segundo o dicionário, seria a "forma de governo em que o povo exerce a sua soberania por intermédio dos seus delegados e representantes e por tempo fixo" ${ }^{\prime 46}$. Então, como é possível que, em uma república, o presidente possa se reeleger indefinidamente? É isso o que aconteceu na Venezuela, tendo todo o processo ocorrido conforme os mecanismos previstos em sua constituição, fruto da corrente constitucional "novo constitucionalismo latino-americano".

Dois dos principais formuladores de dita corrente chegaram a alegar que se a reeleição por tempo indefinido foi incorporada ao texto constitucional da Venezuela, foi por vontade do poder constituinte ${ }^{47}$. Fica claro que Viciano Pastor e Martínez Dalmau manipulam seus argumentos para que não se note o claro caráter antidemocrático de dita corrente constitucional. Se olharmos para o horizonte dos casos concretos, especialmente o caso a que se refere os autores, veremos que tem razão Sebastián Edwards, quando diz que esta corrente

Aceita e promove o uso recorrente de plebiscitos e referendos para poder avançar em suas agendas políticas e sociais. Ou seja, esta doutrina elevou uma das características fundamentais do populismo - a de que o líder populista apela diretamente às massas para obter seus objetivos - a nível constitucional $^{48}$.

A mesma história corre o risco de se repetir no Equador e na Bolívia. No Equador, Rafael Correa, em seu informe à nação, alegou que o seu partido, o movimento Alianza País, tinha a intenção de pedir aos congressistas uma emenda à Constituição para aprovar a eleição por tempo indefinido para todos os cargos de eleição popular. Dentre os argumentos utilizados por Correa, encontra-se o de que

\footnotetext{
46 "REPÚBLICA". Michaelis. Dicionário de Português Online. São Paulo: Editora Melhoramentos, 2009. Disponível em: http://michaelis.uol.com.br/moderno/portugues/index.php?lingua=portuguesportugues\&palavra=rep\%FAblica. Acesso em: 10 de jul. 2015.

47 VICIANO PASTOR, Roberto; MARTÍNEZ DALMAU, Rubén. Fundamentos teóricos y prácticos del nuevo constitucionalismo latinoamericano. Gaceta Constitucional, n. 48, 2011. p. 314.

${ }^{48}$ Tradução própria. EDWARDS, Sebastián. Populismo o mercados: el dilema de América Latina. Bogotá, Norma, 2009. p. 233.
} 
BARROS, Ana Tereza Duarte Lima de; GOMES NETO, José Mario Wanderley. Liberalismo, republicanismo e democracia no marco do novo constitucionalismo latino-americano. Revista Eletrônica Direito e Política, Programa de Pós-Graduação Stricto Sensu em Ciência Jurídica da UNIVALI, Itajaí, v.10, n. 4, 30 quadrimestre de 2015. Disponível em: www.univali.br/direitoepolitica - ISSN 1980-7791.

se estariam aproximando tempos difíceis para a Revolução Cidadã e que existiria uma restauração conservadora em marcha ${ }^{49}$.

Na Bolívia, embora o presidente Evo Morales diga que não pensa em outra reeleição, já chegou a afirmar que a reeleição por tempo indeterminado deve ser algo que venha da vontade popular. Igualmente, já chegou a alegar, aos sindicatos de produtores de coca, que seria difícil encontrar alguém para substituílo, uma vez que esta pessoa teria que conhecer "o povo", como ele conhece. A seção partidária de Cochabamba do MAS, seu partido, chegou a aprovar uma resolução para "trabalhar pela reeleição" de Morales, no ano de $2019^{50}$.

Diante de todo o exposto, não resta dúvidas de que tinha absoluta razão Guillermo O'Donnell, ao afirmar que o republicanismo latino-americano é débil ${ }^{51}$.

\section{FRÁGEIS DEMOCRACIAS}

O novo constitucionalismo latino-americano propõe estabelecer uma democracia não apenas procedimental, mas substantiva. Para os criadores da terminologia, Roberto Viciano Pastor e Rubén Martínez Dalmau, o principal aporte de dita corrente constitucional seria resolver o problema da fraca relação entre poder constituinte e poder constituído. Para isso, mecanismos da democracia participativa garantiriam um "complemento na legitimidade e um avanço na democracia"52. Reconhecem que o papel dos partidos políticos fica limitado "pela ação direta do povo" e que este novo modelo de constitucionalismo consegue superar a tradicional divisão de poderes.

Contudo, ainda que ditos regimes sejam participativos, não se pode dizer que são democracias participativas, pois, como bem dito por Mainwaring, em seu texto

49 CONSTANTE, Soraya. Correa busca a reeleição ilimitada. El País. Quito, 31 de mar. 2014. Disponível em: http://brasil.elpais.com/brasil/2014/05/30/internacional/1401487011_686482.html. Acesso em: 10 de jul. 2015.

50 EL MAS de Bolivia busca la reelección indefinida para Evo Morales. Noticias Montreal. 27 de mai. 2015. Disponível em: http://noticiasmontreal.com/149393/el-mas-de-bolivia-busca-la-reeleccionindefinida-para-evo-morales/. Acesso em: 10 de jul. 2015.

51 O’DONNELL, Guillermo. Disonancias. Críticas democráticas a la democracia. Buenos Aires: Prometeo Libros, 2007. p. 177.

52 Tradução própria. VICIANO PASTOR, Roberto; MARTÍNEZ DALMAU, Rubén. Fundamentos teóricos y prácticos del nuevo constitucionalismo latinoamericano. Gaceta Constitucional, n. 48, 2011. p. 322-326. 
BARROS, Ana Tereza Duarte Lima de; GOMES NETO, José Mario Wanderley. Liberalismo, republicanismo e democracia no marco do novo constitucionalismo latino-americano. Revista Eletrônica Direito e Política, Programa de Pós-Graduação Stricto Sensu em Ciência Jurídica da UNIVALI, Itajaí, v.10, n. 4, 30 quadrimestre de 2015. Disponível em: www.univali.br/direitoepolitica - ISSN 1980-7791.

sobre Hugo Chávez e a política venezuelana, para ser uma democracia participativa é necessário, primeiramente, ser uma democracia ${ }^{53}$. Os supracitados países são exemplos de semidemocracias, sendo a Venezuela, mais especificamente, um caso de autoritarismo competitivo.

Przeworski concorda com Schumpeter e defende um conceito subminimalista de democracia, em que há democracia onde existem eleições livres. Ocorre que Przeworski não leva em consideração que eleições também podem existir em regimes autoritários ${ }^{54}$. É o que Larry Diamond chama de regimes "híbridos" 55 . Ou seja, regimes políticos de caráter predominantemente autoritário, porém, que mantêm eleições para legitimá-los, inclusive com a possibilidade de reeleição. A Venezuela acredito ser o melhor exemplo de democracia que encaminhou para um regime que hoje podemos considerar "híbrido", uma vez que deixou de assegurar o pluralismo e as liberdades individuais. Nesse país, nem as próprias eleições são cem por cento competitivas. Chávez, por exemplo, utilizava os recursos ilimitados que lhe proporcionava o petróleo por meio da PDVSA, mais todos os instrumentos do Estado e os meios de comunicação, aparecendo uma média de cinquenta minutos a mais que seu adversário na televisão e na rádio. Igualmente, na Venezuela, não se pode exercer a atividade política livremente, há pressões, os juízes não são imparciais, não se garante o devido processo legal, nem o direito à liberdade de expressão e de imprensa é pleno. No entanto, há eleições, inclusive com oposição forte, porém, não se dão em condições de igualdade para ambos partidos. Há reeleição, inclusive por tempo indefinido, e, ao invés deste instrumento ter servido para mudar os governantes quando estes começaram suas práticas autoritárias, os ajudou a se perpetuarem no poder.

\footnotetext{
53 MAINWARING, Scott. From representative democracy to participatory Competitive Authoritarian: Hugo Chávez and Venezuelan Politics, Perspective on Politics, vol. 10, n. 4, 2012. p. 959.

${ }^{54}$ PRZEWORSKI, Adam. Minimalist conception of democracy: a defense. In: Shapiro, Ian e HackerCordón, Casiano (org); Democracy's Value. Cambridge University Press, 1999, p. 23-55.

55 DIAMOND, Larry. Elecciones sin democracia. A propósito de los regímenes híbridos. Estudios Políticos. Medellín: Universidad de Antioquia, 2004. v. 24.
} 
BARROS, Ana Tereza Duarte Lima de; GOMES NETO, José Mario Wanderley. Liberalismo, republicanismo e democracia no marco do novo constitucionalismo latino-americano. Revista Eletrônica Direito e Política, Programa de Pós-Graduação Stricto Sensu em Ciência Jurídica da UNIVALI, Itajaí, v.10, n. 4, $3^{\circ}$ quadrimestre de 2015. Disponível em: www.univali.br/direitoepolitica - ISSN 1980-7791.

Já na Bolívia, o pluripartidarismo é uma formalidade, posto que o MAS do presidente Evo Morales é, segundo a classificação de Sartori, um partido hegemónico, e portanto é a única força política de fato ${ }^{56}$.

Para Robert Dahl não se pode chamar de democrático um regime em que há impedimentos para que a oposição se organize em partidos políticos ou que impossibilite a sua competição nas eleições em condições de igualdade. É necessário que o sistema permita a rivalidade entre oposição e governo ${ }^{57}$. Desde este ponto de vista, os processos eleitorais na Venezuela e na Bolívia são considerados antidemocráticos.

Assim, resta evidente que a democracia não pode se resumir a eleições, uma vez que que estas, em lugar de serem o elemento caracterizador da democracia, como supõe Przeworski, servem apenas como instrumento para legitimar o regime, seja ele democrático ou autoritário.

Parece-me muito mais acertada a classificação minimalista de Mainwaring, Brinks e Pérez-Liñán, que defendem ser necessário, além de eleições competitivas, que o regime reconheça o direito ao voto à maioria da população adulta, que as liberdades civis e os direitos políticos sejam protegidos e, por fim, que as autoridades eleitas, de fato, governem, estando os militares sob o controle civil ${ }^{58}$.

A maior contribuição dos autores citados acima foi a criação de uma classificação tricotômica da democracia em que, além da democracia e do autoritarismo puros, existiria um tipo de regime que estaria situado em uma "zona cinzenta", intermediária, a que os autores chamam de semidemocracia.

Brilhante o trabalho feito por Mainwaring, Brinks e Pérez-Liñán. De fato, uma classificação dicotômica seria incompatível com a realidade fática, em especial a latino-americana, em que vários países se situam na zona da semidemocracia, como a Venezuela, a Bolívia e o Equador, e até mesmo o Brasil. O caso mais pragmático seria o da Venezuela, em que, em uma classificação submínima

\footnotetext{
${ }^{56}$ SARTORI, Giovanni. (1976). Partidos y sistemas de partidos. Madrid: Alianza, 1992.

${ }^{57}$ DAHL, Robert. La poliarquía. Participación y oposición. Buenos Aires: REI, 1989. p. 13-15.

58 MAINWARING, Scott; BRINKS, Daniel e PÉREZ-LIÑÁN, Aníbal. Classificando Regimes Políticos na América Latina, Dados, vol. 44, n. 4, 2001. pp. 645-687.
} 
BARROS, Ana Tereza Duarte Lima de; GOMES NETO, José Mario Wanderley. Liberalismo, republicanismo e democracia no marco do novo constitucionalismo latino-americano. Revista Eletrônica Direito e Política, Programa de Pós-Graduação Stricto Sensu em Ciência Jurídica da UNIVALI, Itajaí, v.10, n. 4, 30 quadrimestre de 2015. Disponível em: www.univali.br/direitoepolitica - ISSN 1980-7791.

dicotômica, como a feita por Przeworski, terminaria entrando para o grupo das democracias, uma vez que realiza eleições competitivas. Já se observarmos as outras dimensões da democracia defendidas por Mainwaring, Brinks e Pérez-Liñán, veremos, por exemplo, que o quesito "respeito às liberdades civis" foi violado parcialmente, o que a coloca automaticamente no grupo das semidemocracias. Além do mais, sem uma análise subjetiva seria impossível averiguar se as eleições foram de fato competitivas e, fazendo-se uma análise qualitativa do caso venezuelano, logo se pode observar que, apesar de haver oposição forte e eleições que carregam em si um determinado grau de incerteza, o governo consegue inclinar 0 jogo para 0 seu lado utilizando-se de artimanhas institucionais, como obtendo maior tempo de propaganda eleitoral na TV ou financiando sua campanha com os recursos do petróleo.

Na Venezuela, a crise de representação, como bem explica Mainwaring, fez com que os eleitores votassem em um outsider, Hugo Chávez, que levou uma das mais antigas democracias latino-americanas a migrar para um autoritarismo competitivo. A Venezuela está claramente fora do reino dos regimes democráticos, como bem disseram Javier Corales e Michael Penfold, citados por Mainwaring, dada a centralização do poder, os ataques à oposição que vão além do aceitável em uma democracia, o banimento e o exílio (e a prisão) de políticos da oposição, o uso excepcional dos recursos do setor público e cargos para favorecer amigos políticos e punir oponentes, a demissão em massa dos funcionários públicos que se opuseram a Chávez, o cerceamento da liberdade de imprensa (como quando encerraram as atividades da RCTV), e o aumento da desigualdade na arena eleitoral $^{59}$.

Defendemos que a Venezuela seria um caso de regime autoritário competitivo que, na concepção de Levitsky e Way, seria um regime em que as instituições democráticas formais existem, mas cujos políticos da situação conseguem obter muitas vantagens estatais, colocando-se em vantagem em relação aos oponentes. As eleições são competitivas, mas injustas, uma vez que os candidatos da situação conseguem manipular o processo, como, por exemplo, ao cooptar

\footnotetext{
59 MAINWARING, Scott. From representative democracy to participatory Competitive Authoritarian:
} Hugo Chávez and Venezuelan Politics, Perspective on Politics, vol. 10, n. 4, 2012. p. 956/958. 
BARROS, Ana Tereza Duarte Lima de; GOMES NETO, José Mario Wanderley. Liberalismo, republicanismo e democracia no marco do novo constitucionalismo latino-americano. Revista Eletrônica Direito e Política, Programa de Pós-Graduação Stricto Sensu em Ciência Jurídica da UNIVALI, Itajaí, v.10, n. 4, $3^{\circ}$ quadrimestre de 2015. Disponível em: www.univali.br/direitoepolitica - ISSN 1980-7791.

recursos de empresas estatais e controlar o acesso à mídia. Os partidos da oposição são legais e conseguem funcionar, mas são constantemente perseguidos. As liberdades civis são parcialmente garantidas, mas constantemente desrespeitadas. Em suma, a principal característica desse tipo de regime é a competição desigual ${ }^{60}$.

O livro de Levitsky y Way apenas abarcou o período entre 1990 e 1995, dessa forma, restaram excluídos casos mais recentes de autoritarismo competitivo, como é o caso da Venezuela. Este país, ao ter se militarizado e começado a encarcerar líderes da oposição, faz-nos pensar se já não realizou a transição de um autoritarismo competitivo para uma forma mais pura de autoritarismo.

\section{CONSIDERAÇÕES FINAIS}

O reconhecimento do pluralismo existente na sociedade latino-americana, dotando as minorias étnicas e os povos originários de direitos não antes reconhecidos, foi o carro chefe e o grande triunfo dessas novas constituições latino-americanas. Contudo, sem um Estado que proteja os direitos tradicionalmente promovidos pelo liberalismo (e que chegam a ser, formalmente, assegurados pelas referidas constituições), especialmente os direitos individuais, não há democracia.

O republicanismo, na América Latina, e sobretudo nos países estudados, sofre de grave debilidade. A Venezuela aprovou a reeleição por tempo indefinido, nos levando a questionar se ela ainda seria uma república. Afinal, uma república requer que os governantes eleitos exerçam seu mandato por tempo limitado.

Por fim, ainda que ditos regimes sejam participativos, não se pode dizer que são democracias participativas, pois, para ser uma democracia participativa é necessário, primeiramente, ser uma democracia. Os supracitados países são exemplos de semidemocracias, sendo a Venezuela, mais especificamente, um caso de autoritarismo competitivo.

${ }^{60}$ LEVITSKY, Steven; WAY, Lucan. Competitive Authoritarianism. Hybrid regimes after the Cold War. Cambridge: Cambridge University Press, 2010. p. 5. 
BARROS, Ana Tereza Duarte Lima de; GOMES NETO, José Mario Wanderley. Liberalismo, republicanismo e democracia no marco do novo constitucionalismo latino-americano. Revista Eletrônica Direito e Política, Programa de Pós-Graduação Stricto Sensu em Ciência Jurídica da UNIVALI, Itajaí, v.10, n. 4, $3^{\circ}$ quadrimestre de 2015. Disponível em: www.univali.br/direitoepolitica - ISSN 1980-7791.

\section{REFERÊNCIAS DAS FONTES CITADAS}

ARCAYA, Óscar Godoy. Republicanismo, liberalismo y democracia. Estudios Públicos. n. 99, 2005. p. 241-256.

ARMENGOL, Carlos Manuel Villabella. Constitución y democracia en el nuevo constitucionalismo latinoamericano. IUS. Revista del Instituto de Ciencias Jurídicas de Puebla A.C. n. 25, 2010. p. 49-76.

BARROS, Ana Tereza Duarte Lima de; GOMES NETO, José Mario Wanderley. Nuevo constitucionalismo latinoamericano: una vía para la legitimación del hiperpresidencialismo en las democracias populistas. In: XI Congreso Nacional y IV Congreso Internacional sobre Democracia, 2014, Rosario. Congreso sobre democracia, entre el malestar y la innovación: los nuevos retos para la democracia en América Latina. Rosario: UNR Editora, 2014.

BOLÍVAR, Simón. Escritos Políticos. México: Porrúa, 1986.

$\mathrm{CIDH}$. Informe No. 112/12. Caso 12.828. Fondo Marcel Granier y otros Venezuela. $2012 . \quad$ Disponível em: http://search.oas.org/en/default.aspx?k=Informe+No.+112\%2f12.+Caso+12.828 $\& s=$ All+Sites. Acesso em: 02 de dezembro de 2013.

CONSTANTE, Soraya. Correa busca a reeleição ilimitada. El País. Quito, 31 de mar. 2014.2 Disponível em: http://brasil.elpais.com/brasil/2014/05/30/internacional/1401487011_686482.ht ml. Acesso em: 10 de jul. 2015.

DAHL, Robert. La poliarquía. Participación y oposición. Buenos Aires: REI, 1989.

DIAMOND, Larry. Elecciones sin democracia. A propósito de los regímenes híbridos. Estudios Políticos. Medellín: Universidad de Antioquia, 2004. v. 24.

EDWARDS, Sebastián. Populismo o mercados: el dilema de América Latina. Bogotá, Norma, 2009.

EL MAS de Bolivia busca la reelección indefinida para Evo Morales. Noticias Montreal. 27 de mai. $2015 . \quad$ Disponível em: http://noticiasmontreal.com/149393/el-mas-de-bolivia-busca-la-reeleccionindefinida-para-evo-morales/. Acesso em: 10 de jul. 2015.

FREIDENBERG, Flavia. Los nuevos liderazgos populistas y la democracia en América Latina. Lasa Forum, v. 42, n. 03, 2011. p. 9-11.

GARGARELLA, Roberto. Cambiar la letra, cambiar el mundo. Revista Ecuador Debate, n. 75, 2008. p. 93-96.

máquinas" de la Constitución (1980-2010). Gaceta Constitucional, n. 48, 2011. p. 289-305. 
BARROS, Ana Tereza Duarte Lima de; GOMES NETO, José Mario Wanderley. Liberalismo, republicanismo e democracia no marco do novo constitucionalismo latino-americano. Revista Eletrônica Direito e Política, Programa de Pós-Graduação Stricto Sensu em Ciência Jurídica da UNIVALI, Itajaí, v.10, n. 4, $3^{\circ}$ quadrimestre de 2015. Disponível em: www.univali.br/direitoepolitica - ISSN 1980-7791.

Teoría y filosofía política. latinoamericano. Buenos Aires: CLACSO, 2001.

GARGARELLA, Roberto; COURTIS, Christian. El nuevo consititucionalismo latino-americano: promesas e interrogantes. Santiago: Naciones Unidas, 2009.

JARAMILLO, Svetlana. El nuevo constitucionalismo y los rezagos de la ciencia del Derecho Constitucional latinoamericano. Buenos Aires: CLACSO, 2013.

KELSEN, Hans. (1929). La Démocratie. Paris: Sa Nature - Sa Valeur, 1988.

LEVITSKY, Steven; WAY, Lucan. Competitive Authoritarianism. Hybrid regimes after the Cold War. Cambridge: Cambridge University Press, 2010.

LISSIDINI, A. Democracia directa en Uruguay y en Venezuela: nuevas voces, antiguos procesos. In: Cameron, Hershberg y Sharpe, Nuevas instituciones de democracia participativa en América Latina. México: Flacso, 2012.

MAINWARING, Scott. From representative democracy to participatory Competitive Authoritarian: Hugo Chávez and Venezuelan Politics, Perspective on Politics, vol. 10, n. 4, 2012. p. 955-967.

MAINWARING, Scott; BRINKS, Daniel e PÉREZ-LIÑÁN, Aníbal. Classificando Regimes Políticos na América Latina, Dados, vol. 44, n. 4, 2001. pp. 645-687.

MARSHALL, Tomas. Ciudadania y clase social. Madrid: Alianza Editorial, 1998.

MILLS, J.S. (1859). On Liberty and Other Writings. Cambridge: Cambridge University Press, 1989.

NEGRETTO, Gabriel. La Genealogia del Republicanismo Liberal en América Latina. Alberdí y la Constitución Argentina de 1853. In: Latin American Studies Association. 2001, Washington DC. Anais.

OAS. Ley Orgánica de Participación Ciudadana. 2010. Disponível em: http://www.oas.org/juridico/PDFs/mesicic4_ecu_org6.pdf. Acesso em: 10 de jul. 205.

O’DONNELL, Guillermo. Disonancias. Críticas democráticas a la democracia. Buenos Aires: Prometeo Libros, 2007.

O'DONNELL, Guillermo; SCHMITTER, Philippe. Transiciones desde un gobierno autoritario. Conclusiones tentativas sobre las democracias inciertas. Buenos Aires: Paidós, 1988. v. 4.

OLIVEIRA, Daltro Alberto Jaña Marques; MAGRANI, Eduardo José Guedes; VIEIRA, José Ribas; GUIMARÃES, José Miguel Gomes de Faria Guimarães. Revista Quaestio Iuris, v. 6, n. 2, 2013. p. 185-2014.

ORIO, Luís Henrique. Um novo cenário para novos protagonistas: as ordens políticas do novo constitucionalismo latinoamericano. In: Anais XXII Encontro Nacional do CONPEDI. 2013, Curitiba. Anais. Florianópolis: FUNJAB, 2013. p. 3253. 
BARROS, Ana Tereza Duarte Lima de; GOMES NETO, José Mario Wanderley. Liberalismo, republicanismo e democracia no marco do novo constitucionalismo latino-americano. Revista Eletrônica Direito e Política, Programa de Pós-Graduação Stricto Sensu em Ciência Jurídica da UNIVALI, Itajaí, v.10, n. 4, $3^{\circ}$ quadrimestre de 2015. Disponível em: www.univali.br/direitoepolitica - ISSN 1980-7791.

PRZEWORSKI, Adam. Minimalist conception of democracy: a defense. In: Shapiro, Ian e Hacker-Cordón, Casiano (org); Democracy 's Value. Cambridge University Press, 1999, p. 23-55.

"REPÚBLICA". Michaelis. Dicionário de Português Online. São Paulo: Editora Melhoramentos, $2009 . \quad$ Disponível em: http://michaelis.uol.com.br/moderno/portugues/index.php?lingua=portuguesportugues\&palavra=rep\%FAblica. Acesso em: 10 de jul. 2015.

SANTOS, Boa Ventura de Sousa. Renovar a Teoria Crítica e reiventar a emancipação social. São Paulo: Boitempo, 2007.

SARTORI, Giovanni. (1976). Partidos y sistemas de partidos. Madrid: Alianza, 1992.

SCHUMPETER, Joseph A. [1942] Capitalismo, Socialismo e Democracia. Trad. de Ruy Jungmann. Rio de Janeiro: Fundo de Cultura, 1961, p. 305-344.

VICIANO PASTOR, Roberto; MARTÍNEZ DALMAU, Rubén. Fundamentos teóricos y prácticos del nuevo constitucionalismo latinoamericano. Gaceta Constitucional, n. 48, 2011. p. 307-328.

hablar de un nuevo Constitucionalismo Latinoamericano como corriente doctrinal sistematizada? Universidad de Valencia, 2010.

WOLKMER, Antônio Carlos. Pluralismo e crítica do constitucionalismo na América Latina. In: Anais do IX Simpósio Nacional de Direito Constitucional. 2010, Curitiba.

Anais. Curitiba: ABDConst., 2010. p. 143-155.

Submetido em: Setembro/2015

Aprovado em: Outubro/2015 